\title{
Exploring the Causes of Low-Productivity in Dairy Supply Chain using AHP
}

\author{
Rahul S. Mor ${ }^{*}$, Sarbjit Singh ${ }^{1}$, Arvind Bhardwaj ${ }^{1}$, Shubham Bharti ${ }^{1}$
}

\begin{abstract}
Dairy industry is one of the essential global industries with considerably important implications for world economy where the dairy supply chain (DSC) cover every stage of the food system starting from the milk production at farmer's level to final consumption. For achieving success in the dairy supply chain, it is needed to focus on critical factors (CFs) that are necessary for an organization to achieve its corporate goals with continually improving the operational performance. In this context, the current study is an attempt to identify the critical factors causing low-productivity in dairy supply chain. After comprehensive literature review and pilot study conducted in select dairy industries located in northern region of India, a total of 32 critical factors have been identified. A structured questionnaire has been designed and the data has been collected from select cooperative dairy industries. Further, only eight critical factors have been carried forward for AHP analysis based on the criticality of CFs from collected data. The factor having higher weightage score is considered as major CF. The findings of this study indicate that the poor logistics and transportation facilities is the most critical factor as productivity barrier in the context of cooperative milk processing units in located at northern India. This research study would be useful for the academics as well as for the dairy professionals and managers to manage their production operations effectively by considering the identified CFs.
\end{abstract}

Keywords: Dairy supply chain, analytical hierarchy process (AHP), productivity analysis, critical factors (CFs), cooperative (coop.), infrastructure, logistics and transportation facilities.

\section{Introduction}

India is the largest producer of milk in the world and it is also largest consumer of milk consuming almost its whole milk production. Dairy sector in India has been a significant contributor to the gross domestic product and its value of output has grown significantly. The Indian dairy industry is mainly constituted of 22 state milk federations, 110,000 dairy cooperative societies involving more than 12 million milk producers (NDDB, India). There are some key players in Indian dairy sector as Amul, Britannia, Nestle, Mother Dairy, Verka, Vita, Lakshaya, Nandini etc. the efficiency in the agri-food supply chains can be realized through innovation, supply chain collaboration, elimination of uncertainties, along with lean and green initiatives (Mor et al. [1]). The technology foresight can provide an opportunity to explore the plausible future of dairy industry sector then set to achieve that through appropriate policy initiatives. Therefore, to achieve desired future it is essential to identify the major trends, drivers, actors and factors of the dairy sector. The dairy industry necessities a major development in their efficiency and competitiveness status so as to meet the high quality, consis tency and safety standards of the export markets (Bhardwaj et al. [2]).

\footnotetext{
1 Department of Industrial and Production Engineering, National Institute of Technology, Jalandhar, Punjab 144011, India.

Email: dr.rahulmor@gmail.com,balss@nitj.ac.in, bhardwaja@nitj.ac.in.

* Corresponding author
}

The AHP approach can be utilized and allows the top management to measures the level of uniformity in finding the decision problems (Saaty [3]). AHP is definitely an effective method since it gives the best findings between both tangible and intangible aspects of a judgment. Deng et al. [4] presented the modified TOPSIS, which uses the weighted Euclidean distances rather than representing the weighted decision matrix. The concept of supply chain management emerged as manufacturers experimented with strategic partnerships with their immediate suppliers. Rahul and Kaler [5] conducted a study to identify \& eradicate the causes of poorproductivity in an automotive MNC through the Juran's problem solving technique and lean tools. In addition to the procurement professsionals, experts in transportation and logistics carried the concept of material management a step further to incorporate the physical distribution and transporttation functions, resulting in dairy supply chain management. The word supply chain was primarily coined in 1980s to describe the activities coordinated by an organization to procure and manage supplies (Oliver and Webber [6]). Dairy supply chain starts with procuring the milk from farmer, transportation to plant, milk processing, packaging and distribution to retailers and finally to consumer. Glover et al. [7] concluded that systemic approach is needed to encourage the sustainable practices in dairy supply chain. Indian dairy industry needs development in competitiveness status of the export markets 
(Bhardwaj et al. [2]). Quality management appears to be the most important factor in dairy industry followed by inventtory management, supplier management and technological innovations (Mor et al. [8]). The rural areas consume nearly $50 \%$ of total milk production in India whereas the remaining 50\% of is sold in the domestic market. Out of this $15 \%$, almost $50 \%$ is used as fluid milk, 35\% is used as traditional products (paneer cheese, yoghurt, and milk based sweets), and $15 \%$ is used for the production of butter, ghee, milk powder and other processed dairy products (MoFPI, India). There exists various challenges in Indian dairy sector at all levels. The unorganized dairy market in India is about $80 \%$ and still the milk vendors dominate this section of the market. In this traditional system, the milk produced is directly sold to the consumers at the farm. There is a shortage of refrigerated vans for ferrying the chilled milk to the processing plants. The milk market in India still faces the challenge of getting organized. The unorganized market makes it competes with the organized market in relation to prices. Further, the lack of transparent milk pricing system makes it unremunerated for the producer or farmers.

The analytic hierarchy process (AHP) is applied in this paper to analyze the data. AHP was introduced by Thomas L. Saaty [3], is an effective tool for dealing with complex decision making, and it aids the decision maker to set priorities and make the best decision. By reducing complex decisions to a series of pairwise comparisons, and then synthesizing the results, AHP helps to capture both subjective and objective aspects of a decision. In addition, the AHP includes a procedure for checking the reliability of the decision maker's evaluations, thus reducing the biasness. The AHP consider a set of evaluation criteria and a set of alternative options among which the best decision is to be made. It is important to note that, since some of the criteria could be contrasting, it is not true in general that the best option is the one which optimizes each single criterion, rather the one which achieves the most suitable trade-off among the different criteria. The AHP generates a weight for each evaluation criterion according to the decision maker's pairwise comparesons of the criteria. The higher the weight, the more important is the corresponding criterion. Next, for a fixed criterion, the AHP assigns a score to each option according to the decision maker's pairwise comparisons of the options based on that criterion. Higher the score, better the performance of option with respect to the considered criterion. Finally, the AHP combines the criteria weights and the options scores, thus determining a global score for each option, and a consequent ranking. The global score for a given criteria is the weighted sum of the scores is gained from all the criteria.
Very little work has been conducted to explicitly explore the role of AHP in solving low-productivity problems, especially in the context of dairy industry. To the best of author's knowledge, this study is the first attempt to use the AHP technique for evaluating the priorities among CFs causing lowproductivity in the Indian dairy industry. Thus, the paper explores the various causes of low-productivity in dairy supply chain as critical factors (CFs), and also prioritizing of identified $\mathrm{CFs}$ using the $\mathrm{AHP}$ approach.

\section{Literature Review}

Mangla et al. [9] suggested that for achieving success in food supply chain, it is needed to focus on critical success factors that are necessary for an organization to improve its performance. Dweiri et al. [10] found that the use of AHP in the supplier selection gives the decision maker the confidence of the consistency and the robustness throughout the process. Patushi et al. [11] recommended the cluster development to enhance the business competitiveness and a way for effective utilization of the potential of dairy industry by policy guidance and their management focusing primarily the region of Tirana. Ayodele et al. [12] identified the key research challenges in unpacking and knowledge optimization strategies and their effectiveness in practice. Okano et al. [13] proposed an investigation and classification of the dairy chain to demonstrate that it is possible to organize the estates of the dairy chain, using indicators to rank them. Lemma et al. [14] presented the modeling and optimization approaches used in perishable food supply chain. Nicholas et al. [15] applied the Q methodology to determine the attitudes of low input and organic dairy supply chain members in four European countries to the acceptability of various innovations in dairy farm and dairy supply chain practices. Ghosh et al. [16] studied the risk management involved in the dairy sector with the help of interpretive structural modeling (ISM) tool. Patel et al. [17] argued that the product development that does not occur in isolation as a separate functional activity, rather it is a basic company strategy. Prakash et al. [18] presented a case of the Indian dairy supply chain and demonstrated how balanced score card (BSC) approach may be used to measure its performance. Prasad et al. [19] proposed a model to aid managers who are responsible for making strategic evaluation related to information security issues. Mishra et al. [20] outlined the uncertainties and their impact at various stages of the supply chain along with their impact in the dairy industry. Singh et al. [21] focused on the usage of information technology (IT) by the unorganized retailers for supply chain management of perishable food products in Pune. Punjabi [22] 
presented the factors affecting the competitiveness in the dairy sector by a performance study of five factors as demand conditions, market structure, factor conditions, related supporting industries, and government and the enabling environment.

AHP method is used in the current study to priorities among CFs because AHP the helps to capture both subjective and objective aspects of a decision by reducing the complex decisions to a series of pairwise comparisons and then synthesizing the results. In addition, AHP incorporates a useful technique for checking the consistency of the decision maker's evaluations, thus reducing the bias in the decision making process (Mangla et al. [9]). AHP is a very flexible and powerful tool because the scores, and therefore the final ranking, are obtained on the basis of the pairwise relative evaluations of both the criteria and the options provided by the user. Dweiri et al. [10] found that the use of AHP in the supplier selection gives the decision maker the confidence of the consistency and the robustness throughout the process. Mangla et al. [9] suggested that AHP is a MCDM which is very effective when it comes to analysis of factors and defining ranks. The identification and evaluation of the factors in FSCM adoption is not easy. Chalupakova et al. [23] found that some decisions are spontaneous and others time consuming, requiring detailed information about their implycations. Author used AHP method because AHP can show a detailed version of problem in a structured way. Multi-criteria decision-making methods provide a solution that can be applied to a large variety of problems. Syamsuddin [24] found a decision analysis based on Ternary AHP. This analysis is proposed as a model to aid managers who are responsible in making strategic evaluation related to information security issues. Schotzko et al. [25] addressed the nature of SCM and some difficulties with its implementation in fruits and vegetables, focused largely on the delivery system that is common to the major commodities. The AHP is a very flexible and powerful tool because the scores and final ranking, are obtained on the basis of the pairwise relative evaluations of both the criteria and the options provided by the user (Ananda and Herath [26]). Computations made by AHP are always guided by the decision maker's experience and AHP can thus be considered as a tool that is able to translate the evaluations (both qualitative and quantitative) made by the decision maker into a multi criteria ranking (Hadadian and Rasoulian, [27]). In addition, AHP is simple because there is no need of building a complex expert system with the decision maker's knowledge embedded in it. Macharis et al. [28] conferred the strengths and weaknesses of two MCDM techniques i.e. PROMETHEE and AHP.
After the comprehensive literature review, authors came to know that there exists no research study that explores the critical factors of dairy industry. Further, AHP methods have been used in various areas, but its applications to evaluate the productivity barriers in dairy industry are missing. All the above reasons motivated the authors to design a research problem in current study.

\section{Methods}

The first step of this study is to conduct a comprehensive literature review to collect information on fundamental productivity improvement through supply chain management practices. Pilot study has been conducted in select dairy industries to identify the critical factors causing low-productivity in dairy supply chain. A questionnaire has been designed based on the comprehensive literature review and pilot study. The questionnaire was launched after pre-testing in a coop. dairy industry. Finally, the data was collected from dairy industries located in northern India. The collected data has been analyzed using AHP approach in order to depict the findings of current study. The conclusions, recommendations, and limitations have been derived based upon the results obtained.

\section{Pilot Study}

The pilot study has been divided into two main groups. The first group of participants consists of academic experts in the area of operations \& supply chain management. The second group consists of the industry people of selected coop. dairy industry. Finally, the academic experts and industry top management people were contacted to secure participants for the pilot portion of this study. The data from industries has been collected through personal visits and probing into the perception of industry people about the predominating issues in dairy supply chain.

\section{Questionnaire Design and Survey}

On the basis of literature review and pilot study, a questionnaire is designed considering the factors affecting low-productivity in dairy supply chain. The questionnaire consists of 32 questions related to the low-productivity issues in the different phases like production, procurement, sales and marketing and distribution of dairy products. The top management people of each department have been interviewed and recorded their opinion about the efficiency/ productivity loss due to identified factors on a five point scale. Response scale for the questionnaire is as follows.

5- Very high, 4- High, 3- Moderate, 2- Low, 1- Very low. 
Table 1. Summary of the response' survey

\begin{tabular}{|c|c|c|c|c|}
\hline Q. No & Probable causes of low-productivity in DSCM & Mean & Std.Dev & Gemetric Mean \\
\hline Q1 & Plant downtime (due to High Idle Time, High Inventories, M/c Breakdowns) & 2.18 & 0.59 & 2.10 \\
\hline Q2 & Unbalanced Production Line & 2.32 & 0.57 & 2.25 \\
\hline Q3 & Water/Steam Wastages & 3.45 & 0.96 & 3.32 \\
\hline Q4 & High Machine breakdown & 2.36 & 0.73 & 2.23 \\
\hline Q5 & Over processing due to demand fluctuations & 2.32 & 0.95 & 2.11 \\
\hline Q6 & Unskilled M/c operators & 2.00 & 0.82 & 1.85 \\
\hline Q7 & Poor infrastructure (Cold chain and Transportation facilities) & 3.32 & 0.99 & 3.10 \\
\hline Q8 & Production Process not followed properly & 2.00 & 0.82 & 1.84 \\
\hline Q9 & High Production cost & 1.95 & 0.65 & 1.84 \\
\hline Q10 & Adulterated/contaminated raw milk & 1.45 & 0.74 & 1.33 \\
\hline Q11 & Unsatisfied shop floor employees & 3.32 & 1.09 & 3.11 \\
\hline Q12 & Unplanned Order Preference & 2.59 & 0.73 & 2.48 \\
\hline Q13 & Milk wastages during processing & 3.27 & 1.24 & 2.99 \\
\hline Q14 & Inefficient Cold chain and Transport facilities & 3.64 & 0.58 & 3.58 \\
\hline Q15 & Lack of Infrastructure at society level & 2.77 & 0.75 & 2.66 \\
\hline Q16 & Improper Demand Forecast & 3.05 & 0.79 & 2.94 \\
\hline Q17 & Production losses due to $\mathrm{m} / \mathrm{c}$ maintenance issues & 2.41 & 0.67 & 2.32 \\
\hline Q18 & Unnecessary motion/movement of operators & 2.64 & 0.95 & 2.46 \\
\hline Q19 & More Waiting time at Packaging line & 3.27 & 0.94 & 3.11 \\
\hline Q20 & Unnecessary labor hours & 2.59 & 0.96 & 2.37 \\
\hline $\mathrm{Q} 21$ & Outdated machine technology & 3.09 & 0.75 & 3.00 \\
\hline Q22 & Improper information flow at societies as well as in Plant level & 2.36 & 0.73 & 2.23 \\
\hline Q23 & Traceability of milk quality issues & 2.36 & 0.95 & 2.16 \\
\hline Q24 & Operator Negligence & 3.59 & 1.05 & 3.44 \\
\hline Q25 & Unskilled Maintenance personnel & 1.82 & 0.66 & 1.70 \\
\hline Q26 & Lack of automation in plant & 3.86 & 0.64 & 3.81 \\
\hline $\mathrm{Q} 27$ & Milk wastage due to Demand Fluctuations & 2.41 & 0.80 & 2.24 \\
\hline Q28 & Reprocessing of milk due to leakages, unsealed packaging, $\mathrm{m} / \mathrm{c}$ breakdown & 3.41 & 0.80 & 3.31 \\
\hline Q29 & No provision for traceability of $\mathrm{m} / \mathrm{c}$ breakdown & 2.09 & 0.68 & 1.97 \\
\hline Q30 & Frequent Power cuts and failures & 1.55 & 0.60 & 1.44 \\
\hline Q31 & $\begin{array}{l}\text { No culture of Data backup at any level in plant (like Log book entry for } \\
\text { Production, Maintenance, M/c Breakdown etc.) }\end{array}$ & 2.14 & 0.83 & 1.95 \\
\hline Q32 & Leakage of milk, water and steam through pipelines and joints & 2.73 & 0.55 & 2.67 \\
\hline
\end{tabular}

\section{Data Collection}

Out of the 34 responses (10 from academics and 24 from dairy industry) collected from the survey, a total of 22 responses (6 from academics and 16 from dairy industry) have been considered for AHP analysis. Some responses were neglected due to incomplete information and only 22 were considered based on their accuracy level of responses received. The respondents include academicians working in the area of operations and supply chain management, whereas, the industry people include the shop floor executives and top level managers from different departments such as procurement, production, distribution, marketing etc. $\mathrm{A}$ to $\mathrm{V}$ are the respondents, and $\mathrm{Q} 1$ to $\mathrm{Q} 32$ indicate the questions related to low-productivity in the dairy supply chain (Table 1).

\section{AHP Methodology}

AHP methodology has been used to support multi criteria decisions, where the problem is divided into different components i.e. analytical and hierarchy.
Various steps being followed in the AHP approach are as follows: (1) Formulation of the objective: Evaluating the critical factors in order to identify their related priority in the successful implementtation of DSCM initiatives in supply chains. (2) Forming pairwise assessment matrix: Pairwise assessment matrix has been formed based on respondent's feedback. The pairwise assessment matrix among the factors is accomplished through a Saaty's scale. (3) Determination of Eigen values \& Eigen vectors and comparative importance weights: The framed pairwise comparison matrices were operated to establish the Eigen values and Eigen vectors, which were further analyzed to calculate the relative importance weights of the factors. (4) Assessment of the Consistency Ratio: The consistency ratio (CR) has been calculated to ensure the reliability of pairwise comparisons. Mathematical expression for calculating the $\mathrm{CR}$ is given as, $\mathrm{CR}=\mathrm{CI} / \mathrm{RI}$, where the consistency index is denoted by $(\mathrm{CI})=\left(\lambda_{\max }-\mathrm{n}\right) /(\mathrm{n}$ $1), \lambda_{\max }$ is the maximum average value and the value of random consistency index (RI) depends upon the value of (n). The value of CR must be less than 0.10 to have improved level of consistency. 


\section{Results and Discussions}

\section{Data Analysis}

A thorough survey has been conducted by getting responses in a questionnaire developed with a set of questions regarding CFs in dairy supply chain. Table- 1 shows the questions (Q1 to Q32) along with responses (A to $\mathrm{V}$ ) received. After identifying the $\mathrm{CFs}$, their ranking has to be done as per their criticality using AHP. This technique is very reliable and simple as well as effective over the other MCDM techniques.

The data obtained through the survey has been analyzed in MS-Excel to rank critical factors. This analysis highlighted the key CFs hindering the productivity of dairy supply chain.

\section{Ranking of Factors}

AHP is a multi-criteria decision making technique used to find the ranking of priorities and alternatives. AHP is used in this study to define the weights or Eigen values of factors and then rank them accordingly. In this method, we prepare a pairwise comparison matrix between the criteria called priority matrix and their weights has been defined in another matrix called normalized matrix or weight matrix. This method of defining weight is called the weighted average method. AHP steps followed are as below: (1) Formulation of the objective. (2) Forming pairwise assessment matrix. (3) Determination of the Eigen values and Eigen vectors and comparative importance weights. (4) Assessment of the Consistency Ratio.

The criticality of identified CFs has been derived based on pairwise assessment matrix of the responses received from 22 respondents. The count and valid percentage given by respondents is used to find out the most ciritical factors (i.e. factors with very high rating). It is evident that out of the $32 \mathrm{CFs}$, only 8 factors illustrates the values with very high criticality (Figure 1); 22 factors illustrates the values with high criticality (Figure 2); 31 factors illustrates the values with moderate criticality (Figure 3); 31 illustrates the values with low criticality (Figure 4); and 24 factors illustrates the values with very low criticality (Figure 5).

Criticality is calculated based on the total Count of each of five scale (1 to 5) given by individual respondent and their Valid Percentage.

For eg. Q32 is rated as Low (2) by 7 respondents (32\%); Moderate (3) by 14 respondents (64\%); High by 1 respondent (5\%). Thus, Q32 comes under 3 categories, and so is the case with other factors also.
As per criticality analysis of the responses received from 22 respondents, there are 24 factors having Very Low criticality. Further, 31 factors having Low criticality; 31 factors having Moderate criticality; 22 factors with High criticality; and 8 factors having Very High criticality

Finally, eight CFs have been shortlisted based on the criticality and extended review, which were further authenticated in discussion with experts from academics and industry. AHP approach has been used to demonstrate the rank of the critical factors mentioned below: Water and Steam Wastages (WSW). Poor infrastructure (cold chain logistics and transport facilities) (LI). Poor employee welfare schemes (WS). Poor infrastructure at milk collection points (IS). More waiting time at milk packaging line (WT). Traceability of quality issues (MT). Operator's Negligence (ON). Lack of Automation in plant (LA).

\section{Prioritizing of Factors through AHP}

AHP is used as a multi-criteria decision making technique to find the ranking of priorities and alternatives. Here, AHP is defines the weights or Eigen values of the factors, and then rank them accordingly. In this method, we prepare a pairwise comparison matrix between the criteria called priority matrix and then define their weights in another matrix called normalized matrix or weight matrix. This method of defining weight is called the weighted average method. The judgment is considered consistent when $\lambda_{\max }$ is close to the criteria (n), the values of Consistency Index (CI), Random Inconsistency (RI), and Consistency Ratio (CR). If $\mathrm{CR} \leq 0.1$, the consistency ratio of $\mathrm{A}$ is acceptable.

Analysis of critical factors affecting the productivity of dairy industry has been handled with AHP. Eight critical factors have been shortlisted from the analysis results mentioned above. AHP approach had been used to demonstrate the rank of the critical factors and is mentioned in Table 2. This matrix depicts the relative comparison between eight factors is made here.

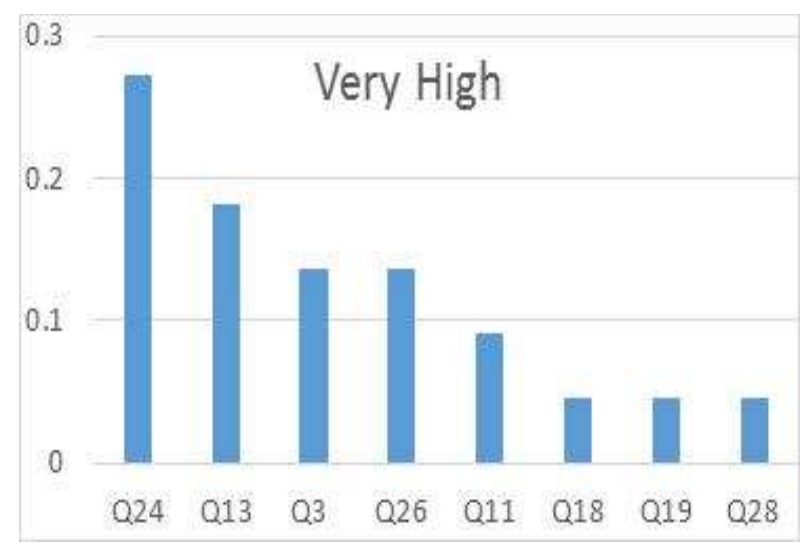

Figure 1. Factors with very high criticality 


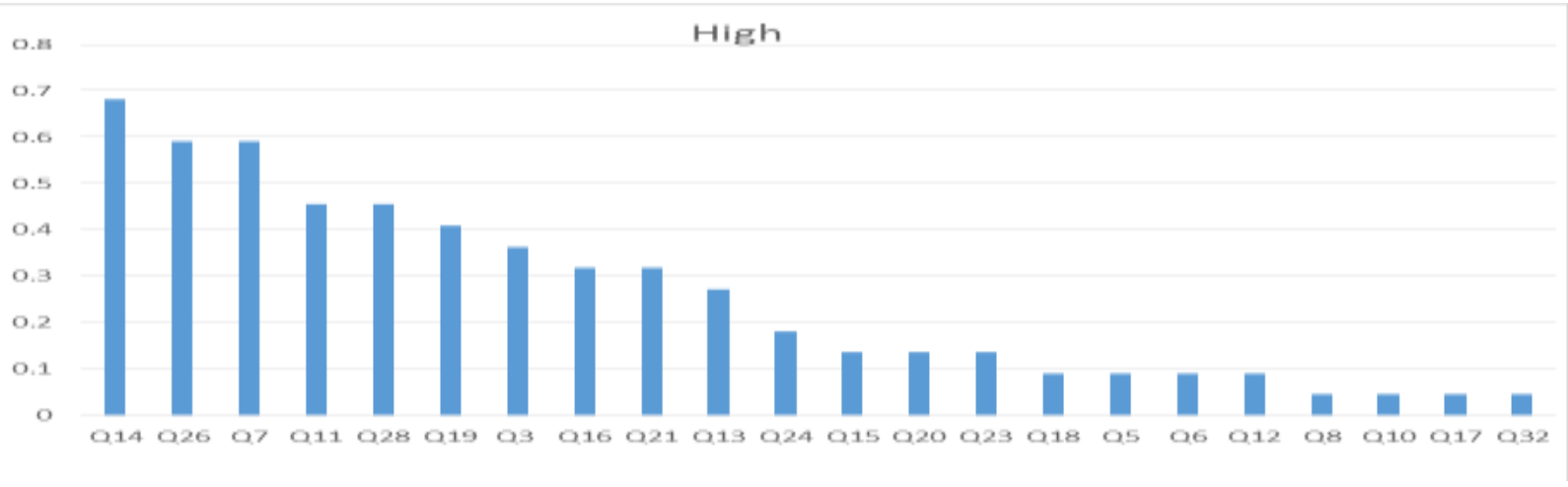

Figure 2. Factors with high criticality

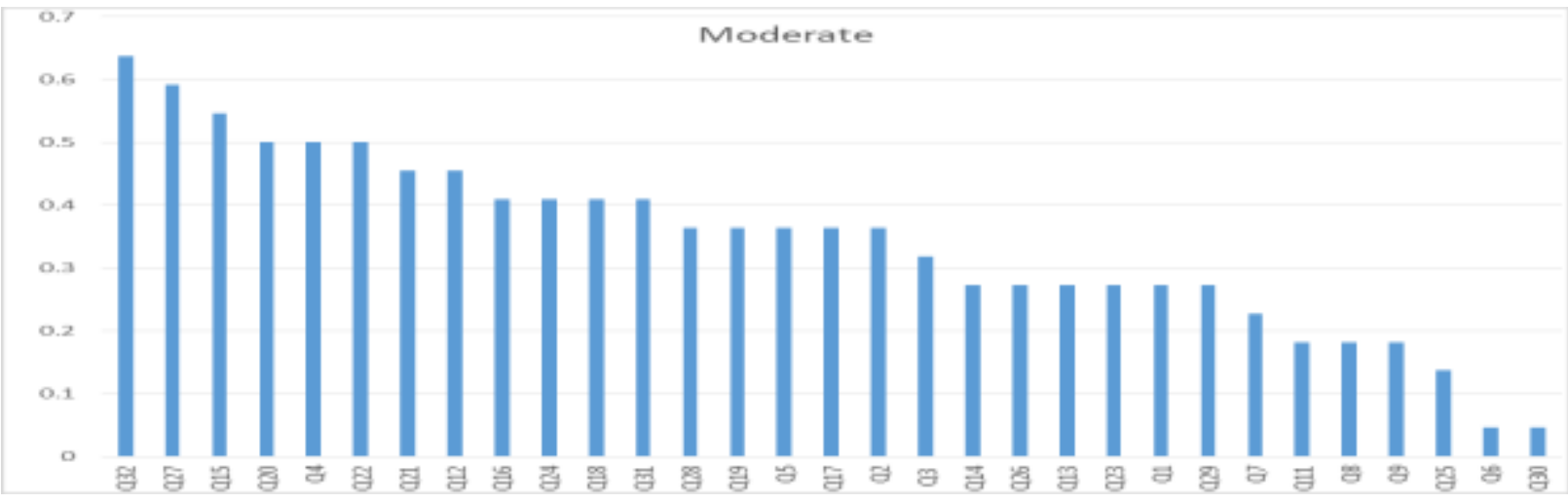

Figure 3. Factors with moderate criticality

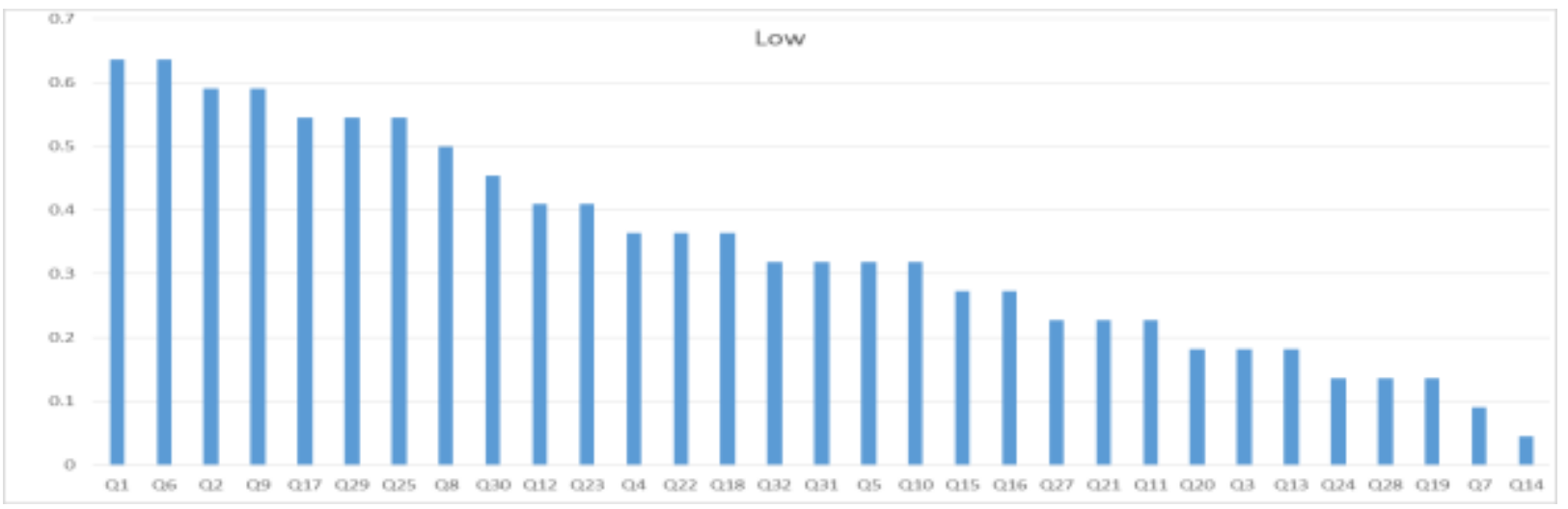

Figure 4. Factors with low criticality

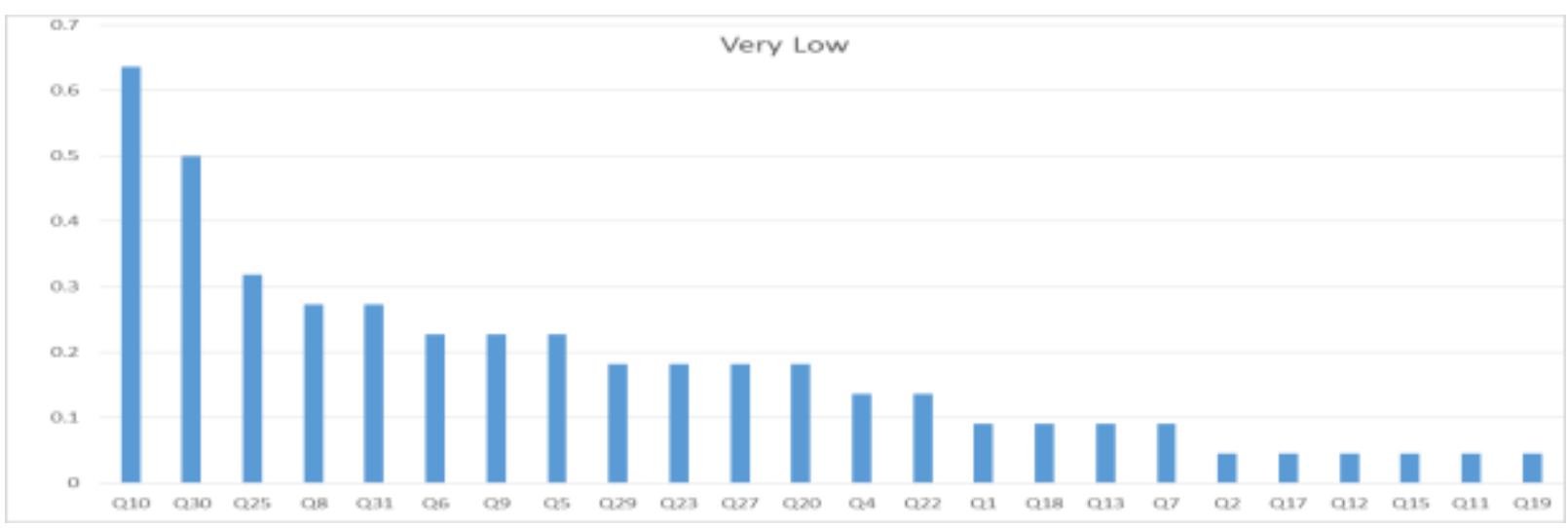

Figure 5. Factors with Very Low Criticality 
Table 2. AHP priority matrix (A)

\begin{tabular}{ccccccccc}
\hline Factors & WSW & LI & WS & IS & WT & MT & ON & LA \\
\hline WSW & 1 & 0.33 & 0.50 & 0.33 & 0.5 & 0.50 & 1.00 & 0.33 \\
LI & 3 & 1.00 & 3.00 & 2.00 & 3 & 3.00 & 0.33 & 2.00 \\
WS & 2 & 0.33 & 1.00 & 3.00 & 5 & 2.00 & 3.00 & 1.00 \\
IS & 3 & 0.50 & 0.33 & 1.00 & 3 & 3.00 & 2.00 & 1.00 \\
WT & 2 & 0.33 & 0.20 & 0.33 & 1 & 2.00 & 0.50 & 0.33 \\
MT & 2 & 0.33 & 0.20 & 0.20 & 0.5 & 1.00 & 0.33 & 0.33 \\
ON & 1 & 3.00 & 0.33 & 0.50 & 2 & 3.00 & 1.00 & 2.00 \\
LA & 3 & 0.50 & 1.00 & 1.00 & 3 & 3.00 & 0.50 & 1.00 \\
Total & 17 & 6.33 & 6.57 & 8.37 & 18 & 17.50 & 8.67 & 8.00 \\
\hline
\end{tabular}

Table 3. AHP normalized matrix $(\mathrm{N})$

\begin{tabular}{cccc}
\hline Sr. No. & Factors & Weights (W) & Ranks \\
\hline 1 & WSW & 0.055104796 & 7 \\
2 & LI & 0.207102340 & 1 \\
3 & WS & 0.193043247 & 2 \\
4 & IS & 0.139945720 & 4 \\
5 & WT & 0.063722047 & 6 \\
6 & MT & 0.048711089 & 8 \\
7 & ON & 0.161369302 & 3 \\
8 & LA & 0.131001460 & 5 \\
\hline \multicolumn{5}{c}{ Total } & 1 & \\
\hline
\end{tabular}

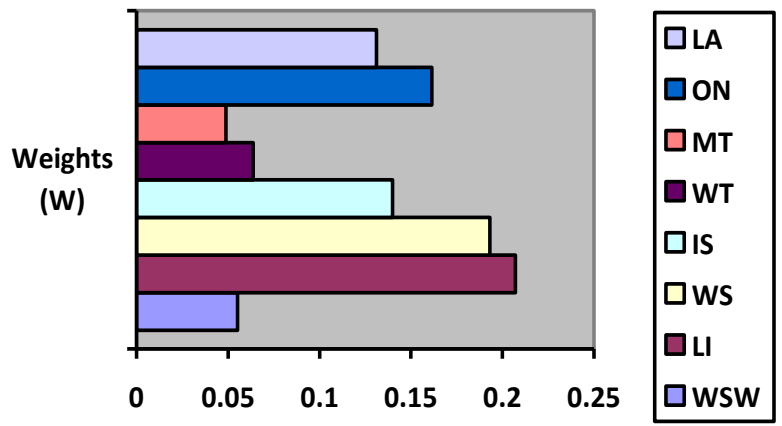

Figure 6. Weight percentage of factors

The sum of the columns $\mathrm{A}=(17,5.81,6.56,8.36$, $16.83,18.5,8.5,8)$. To check for the consistency of the priority matrix (experts opinion), a normalized matrix " $\mathbf{N}$ " is found by dividing each element of the matrix $\mathbf{A}$ by the sum of the respected column (Table2). To find the weight of each criteria a matrix ' $W$ " is found by calculating the average for each row of the matrix “N" (Table- 3).

Finally, the weight percentage of individual factors used for AHP is calculated. Figure- 6 depicts the weight percentage chart for critical factors. It is evident that the $\mathrm{CF}$ logistics and transportation facilities' have highest value in weight percentage matrix.

Notice that,

$$
\sum \mathrm{W}_{\mathrm{i}}=1
$$

To check for the consistency of the decision maker judgment, the Eigen value $\left(\lambda_{\max }\right)$ is found as:

$$
\lambda_{\max }=9.132946052
$$

The judgment is considered consistent when $\lambda_{\max }$ is close to the criteria (n). Here, the values of CI, RI, and CR comes out to be $0.161849436,1.485$, and 0.10 respectively.

Since $\mathrm{CR} \leq 0.1$, the consistency ratio of 'A' is acceptable. The priority order of the above factors is given as:

$$
\mathrm{LI}>\mathrm{WS}>\mathrm{ON}>\mathrm{IS}>\mathrm{LA}>\mathrm{WT}>\mathrm{WSW}>\mathrm{MT}
$$

\section{Discussion}

The AHP analysis illustrates that poor infrastructure (cold chain logistics \& transportation facilities) is the major cause of low-productivity in dairy supply chain. Further clarification of the findings of this study are as follows.

Poor logistics and transportation facilities (LI): It is ranked first and has the highest priority in comparison to other factors. Logistics and transportation influence the organizational performance hugely and it occupies one-third of overall product cost. It is required in the whole production procedures, from manufacturing to delivery to the final consumers and returns. Poor logistics and transportation facilities are the main problems for Indian dairy industry.

Poor welfare schemes (WS): It is ranked second in the priority list and plays an important role in implementing the effective supply chain management practices. Welfare schemes are necessary for the smooth flow of supply chain because it maintains the morale and efficiency of employees which upsurges the overall productivity of industry as well. Top level managers working in dairy industry should ensure a safe and hygienic working environment for employees and high social welfare and training for all employees involved in the food chain. The state milk federation and govt. should take revolutionary initiatives in promoting farmer's welfare.

Operator negligence $(\mathrm{ON})$ : It is one of the critical issue that Indian coop. dairy industry is facing. Negligence results in associated risks of decreasing productivity, decreasing product quality, financial loss and late delivery of dairy products. The operators are responsible for maintenance the production target as well as the optimum product quality parameters at particular workstation. This critical issue can be resolved by offering extra perks and incentive schemes to the operators which further lead to enhanced morale of operators.

Infrastructure at milk collection points (IS): It is ranked fourth in comparison to other factors. The infrastructure at milk collection points or at society 
level needs to be up to the mark because the milk is first collected at these points and checked for quality measures (i.e. fat and SNF). The societies needs to be fully equipped with latest technology so that the farmers can get good price per for raw milk and the milk quality can remain up to the mark. Also the societies should be equipped with effective cold chain infrastructure through milk chillers for achieving improved procurement performance.

Lack of automation in plant (LA): Automation is the main necessity of current industrial world. Automation helps in increasing profit and reducing manual work which leads to less investment of labor and larger profits. But even now Indian dairy industry is not willing to invest in automation techniques and still wants to go for manual operations. Automation and intelligent business processes deliver responsiveness and agility in supply chain process. Automated inventory tracking like automated milk collection units (AMCU), RFID technology and data processor-based milk collection units (DPMCU) at society level along with effective information systems can help Indian dairy industry to to compete with other international dairy brands.

Waiting time at milk packaging line (WT): This issue is another big problem due to very old packaging line and the chain conveyor used is an outdated technology. Frequent breakdown occurs five to six times a day which causes a major halt in the packaging line. Production managers need to change the layout of packaging line, replace the chain conveyor with belt conveyor system which can reduce packaging time as well labor cost.

Water and steam wastages (WSW): Water is a major commodity in today's world and is being used in each and every industry sector. Wastages of water and steam at shop floor takes place due to leakage of from gaskets, valves and pipe joints etc. Water management initiatives should promote continuous improvement in the form of reducing water consumption, effective waste water treatment etc. Dairy industries need to pay a proper attention towards the issues through proper and preventive maintenance of machinery and pipelines.

Traceability of milk quality issues (MT): Dairy industry needs a proper milk quality traceability mechanism so as to maintain the quality standards of export market. An effective traceability system is an essential tool to manage food quality, food safety and to stimulate the effective supply chain management practices in dairy industry. Dairy industries still use the traditional methods of quality by manual checking at every single point and then records are sent to the managers in the form of printed slips. They need a proper system for networking and linking the whole plant as well as societies through a single network so as to trace and solve the quality issues easily.

\section{Conclusion}

For the developing as well as the developed nations, a huge importance has been given to the adoption of supply chain management in dairy industry. Technological innovations pushes the developing nations towards implementing DSCM practices in order to maximize their economic gains and reduce the environmental impact. The aim of this study is to propose a structural framework for the evaluation of critical factors for DSCM using AHP approach. After a comprehensive literature survey and pilot study, eight critical factors were selected for analysis. The CFs were analyzed for their criticality. The outcome reveals that the poor logistics \& transportation (LI) facilities stands first, and the traceability of milk quality issues (MT) stands at eighth rank in the list of identified CFs causing low-productivity in dairy industry. The relative importance order of the critical factors is carried out as: $\mathrm{LI}>\mathrm{WS}>\mathrm{ON}>\mathrm{IS}>$ $\mathrm{LA}>\mathrm{WT}>\mathrm{WSW}>\mathrm{MT}$. In conclusion, the managers and practitioners in dairy industry needs to pay more attention towards CFs so as to increase the effectiveness of dairy supply chain practices and to achieve their long term corporate goals.

The proposed framework is an attempt to capture the dynamics of dairy industry and to incorporate the constraints related to productivity. The framework developed in this study has been tested in a coop. milk processing unit located at northern India and also discussed with the experts from academics. This research work has its practical as well as managerial implications in dairy industry. This will help practitioners, regulators and dairy professionals to focus their efforts towards achieving high organizational performance through implementation of effective supply chain management practices.

This model has its own limitations which authors wants to highlight here. However, this methodology may be applied to multiple case studies of other agrifood processing industries. This study can further be expanded for a comparison between private and cooperative dairy industries as future scope in this context.

\section{Acknowledgments}

The authors would like to thank all the respondents from dairy industry. Further, authors would like to express their sincere gratitude for the remarks and suggestions made by the anonymous reviewers and Editor of JTI, which radically improved this paper. 


\section{References}

1. Mor, R.S., Singh, S., Bhardwaj, A. and Singh, L.P. Technological Implications of Supply Chain Practices in Agri-Food Sector: A Review. Int. Journal of Supply and Operations Management, 2(2), 2015, pp. 720-747.

2. Bhardwaj, A., Mor, R.S., Singh, S. and Dev, M., An Investigation into the Dynamics of Supply Chain Practices in Dairy Industry: A Pilot Study. Proceedings of the 2016 International Conference on Industrial Engineering and Operations Management, Detroit, Michigan, USA, Sept. 23-25, 2016, pp. 1360-1365.

3. Saaty, T.L., The Analytic Hierarchy Process: Planning, Priority Setting, Resource Allocation, New York: McGraw, 1980.

4. Deng, H., Yeh, C.H. and Willis, R.J, InterCompany Comparison using Modified TOPSIS with Objective Weights. Computational Operation Research 27, 2000, pp. 963-973.

5. Rahul and Kaler, J.S., Eradication of Productivity Related Problems through Lean Principles in Integrated Manufacturing Environment, International Journal of Lean Thinking, 4(1), 2013, pp.71-88.

6. Oliver, R.K. and Webber, M.D., Supply-Chain Management: Logistics Catches Up with Strategy, Outlook, 5(1), 1982, pp. 42-47.

7. Glover, J.L., Daniels, D.C. and Dainty, A.J., An Institutional Theory Perspective on Sustainable Practices across Dairy Supply Chain. International Journal of Production Economics, 152, 2014, pp. 102-111.

8. Mor, R. S., Bhardwaj, A. and Singh, S., Framework for Measuring the Procurement Performance in Dairy Supply Chain. Joint Indo-German Conference on Sustainable Engineering, Sept. 1516, 2017 at BITS Pilani, Pilani Campus, and Accepted for Springer Book Proceedings.

9. Mangla, S.K., Sharma, Y.K., Patil, P.P., Using AHP to Rank the Critical Success factors in Food Supply chain management, International Conference on Smart Strategies for Digital World Industrial Engineering Perspective, 58, 2016.

10. Dweiri, F, Kumar, S, Khan, S.A, Jain, V., Designing an Integrated AHP Based Decision Support System for Supplier Selection in Automotive Industry. Expert Systems with Applications, 62, 2016, pp. 273-283.

11. Patushi, S. and Kume, V., The Development of Clusters as a Way to Increase Competitiveness of Businesses: Case of Milk Processing Industry in Tirana, European Scientific Journal, 10(13), 2014, pp. 98-116.

12. Ayodele, A.B., Ellis, L. and Turner, P., Identifying Key Research Challenges in Investigating Knowledge Optimization Strategies in Perishable Food Chains, $11^{\text {th }}$ International Conference on Intellectual Capital, Knowledge Management \& Organi- zational Learning- ICICKM 2014, University of Sydney, Australia.

13. Okano, M.T., Vendrametto, O. and Santos, O.S., How to Improve Dairy Production in Brazil through Indicators for the Economic Development of Milk Chain, Modern Economy, 5, 2014, pp. 663-669.

14.Lemma, Y., Kitaw, D. and Gatew, G., Loss in Perishable Food Supply Chain: An Optimization Approach Literature Review, International Journal of Scientific \& Engineering Research, 5(5), 2014, pp. 302-311.

15. Nicholas, P., Mandolesi, S., Naspetti, S. and Zanoli, R., Innovations in Low Input and Organic Dairy Supply Chains: What is Acceptable in Europe? Proceedings of the $4^{\text {th }}$ ISOFAR scientific Conference, 'Building Organic Bridges', Organic World Congress 2014, 13-15 Oct., Istanbul, Turkey, pp. 1167-1170.

16. Mor, R. S., Singh, S., and Bhardwaj, A., Framework for Measuring the Procurement Performance in Dairy Supply Chain. Joint Indo-German Conference on Sustainable Engineering, Sept. 1516, 2017 at BITS Pilani, Pilani Campus, and Accepted for Springer Book Proceedings.

17. Patel, A.M, Modha, H.M., Patel, D.K and Patel, H. G., New Product Development- Opportunities and Challenges for Traditional Indian Dairy Products, National Seminar on Indian Dairy Industry - Opportunities and Challenges, $A A U$, Anand, 2014, pp. 228-232.

18. Prakash, G. and Pant, R.R., Performance Measurement of a Dairy Supply Chain: A Balance Scorecard Perspective, Proceedings of the 2013 IEEE IEEM, pp. 196-200.

19. Prasad, R. and Satsangi, R., A Case Study of Amul Cooperative in India in Relation to Organizational Design and Operational Efficiency, International Journal of Scientific \& Engineering Research, 4(1), 2013, pp. 1-9.

20. Mishra, P.K. and Shekhar, B.R., Impact of Risks and Uncertainties on Supply Chain: A Dairy Industry Perspective, Journal of Management Research, 3(2), 2011, pp. 1-18.

21. Singh, N. and Javadekar, P., Supply Chain Management of Perishable Food Products: A Strategy to Achieve Competitive Advantage through Knowledge Management, Indian Journal of Marketing, 41(10), 2011, pp. 3-9.

22. Punjabi, M., India: Increasing Demand Challenges the Dairy Sector, Smallholder Dairy Development: Lessons Learned Asia. RAP Publication, 2009/02, Assessed Online 15/07/2017 at 15:55 http://www.fao.org/docrep/011/i0588e/I0588 E05.htm.

23. Chalúpková, E. and Franek, J., Application of the Analytic Hierarchy Process Method in a Comparison of Financial Leasing and Loans, Ekonomická Revue-Central European Review of Economic Issues, 17, 2014, pp.75-84. 
24. Syamsuddin, I., Multicriteria Evaluation and Sensitivity Analysis on Information Security. International Journal of Computer Applications, 69(24), 2013, pp. 22-25.

25. Schotzko, R.T. and Hinson, R.A., Supply Chain Management in Perishables: A Produce Application, Journal of Food Distribution Research, 31(2), 2000, pp. 17-25.

26. Ananda, J. and Herath, G., The Use of Analytical Hierarchy Process to Incorporate Stakeholder Preference into Regional Forest Planning, Forest Policy and Economics, 5(1), 2003, pp.13-26.
27. Hadadian, A.R. and Rasoulian, A., Using Analytic Hierarchy Process (AHP) for Selecting the Appropriate Country for Economic Integration: Case of Iran's Foreign Trade with OIC Countries. International Research Journal of Finance and Economics, 162, 2017, pp. 24-32.

28. Macharis, C., Springael, J., De Brucker, K. and Verbeke, A., PROMETHEE and AHP: The Design of Operational Synergies in Multicriteria Analysis: Strengthening PROMETHEE with Ideas of AHP, European Journal of Operational Research, 153(2), 2004, pp. 307-317. 